Int. J. Dev. Biol. 57: 221-223 (2013)

doi: 10.1387/ijdb.130145jt

\title{
Carcinoma in situ -from clinical observation to a paradigm shift for testicular carcinogenesis
}

\author{
JORMA TOPPARI* \\ Departments of Physiology and Paediatrics, University of Turku, Turku, Finland and \\ Department of Growth and Reproduction, Rigshospitalet, Copenhagen, Denmark
}

\begin{abstract}
Carcinoma in situ in the testis has its origin in the fetal gonad and leads to testicular cancer in young adulthood. It can be detected in a testicular biopsy and treated with irradiation, which can preserve testosterone production of the man. These are the key findings of Niels E. Skakkebaek that changed our view of testicular tumourigenesis during the last fifty years. These and other findings are discussed in this interview-based review of testicular germ cell cancer.
\end{abstract}

KEY WORDS: testis, cancer, fertility, CIS, germ cell

I have had the privilege to collaborate with Niels E. Skakkebaek (Fig. 1) on testis research for a long time. Over the years we have often discussed the development of science and particularly progress in testicular cancer research. I will here describe the exciting history how the recognition of carcinoma in situ of the testis lead to a paradigm shift in our understanding of testicular tumourigenesis and subsequent changes in management of patients at risk of testicular germ cell cancer.

As a young medical doctor Niels E. Skakkebaek started a research project on meiotic chromosomes in infertile men. He soon realized that good histopathology and microscopy of the testicular structure were essential for this work and he looked for the best possible teacher of testicular histology. Professor Yves Clermont at McGill University in Montreal had characterized both human and rodent spermatogenic cells in detail, and it was in his laboratory where Skakkebaek got a short but intensive training in morphology of germ cells. This knowledge was instrumental when he examined testicular biopsies from the infertile men. He recognized abnormal germ cells in testicular sections of two infertile men, details of which were published in APMIS (Skakkebaek, 1972). He wanted to perform further studies using EM technique on these two cases and by the time of second biopsy some years after the first one had been obtained both men had developed embryonal carcinoma and the abnormal germ cells were also found in the areas around the tumour. This finding gave Skakkebaek the idea that the abnormal cells in the first biopsy of both patients possibly had been precursor cells of testicular germ cell cancer and Skakkebaek therefore called the abnormal cell pattern carcinoma in situ (CIS) of the testis. The hypothesis was published in a paper in The Lancet in 1972 (Skakkebaek, 1972b), where he also presented evidence that the CIS cells were hyperdiploid. Electron microscopic investigations which followed confirmed that the CIS cells were different from spermatogenic cells and similar to primordial germ cells or gonocytes (Nielsen et al., 1974). He then turned to archive specimens of both seminomas and non-seminomas and found CIS like tubules in the adjacent 'normal' testicular tissue of both seminomas and non-seminomas (Skakkebaek, 1975). Still, urologists and oncologists were not completely convinced that these cells were pre-invasive and malignant. However, a prospective study of patients with CIS detected by chance during infertility-workup showed that some developed seminomas, others non-seminomas (Skakkebaek, 1978) and Skakebaek was now convinced that seminomas and non-seminomas had a common origin from CIS cells. To convince pathologists and urologists he organized together with Jakob Visfeldt and Kenneth Grigor, two pathologists, a workshop in 1980 with both practical microscopy sessions and lectures on CIS and testis cancer, all published in the proceedings Early Detection of Testicular Cancer (Fig. 2). Prominent testis cancer researchers participated. The workshop which was reported in an editorial in the Lancet convinced most people, but not all, that CIS was a precursor of both non-seminomas and seminomas. However, several pathologists in the USA remained sceptical for many years. A reason might be that atypical germ cells around testicular tumours had been noticed and also reported now and then by pathologists and not considered significant, most often just assumed to be effects of tumour. However, by the time another Copenhagen workshop was arranged in 1986 by Skakkebaek's

Abbreviations used in this paper: CIS, carcinoma in situ. *Address correspondence to: Jorma Toppari. Departments of Physiology and Paediatrics, University of Turku, Kiinamyllynkatu 10, FI-20520Turku, Finland.
Tel: +35-85-0414-0116. E-mail: jorma.toppari@ utu.fi

Final, author-corrected PDF published online: 5 June 2013.

ISSN: Online 1696-3547, Print 0214-6282

(C) 2013 UBC Press

Printed in Spain 


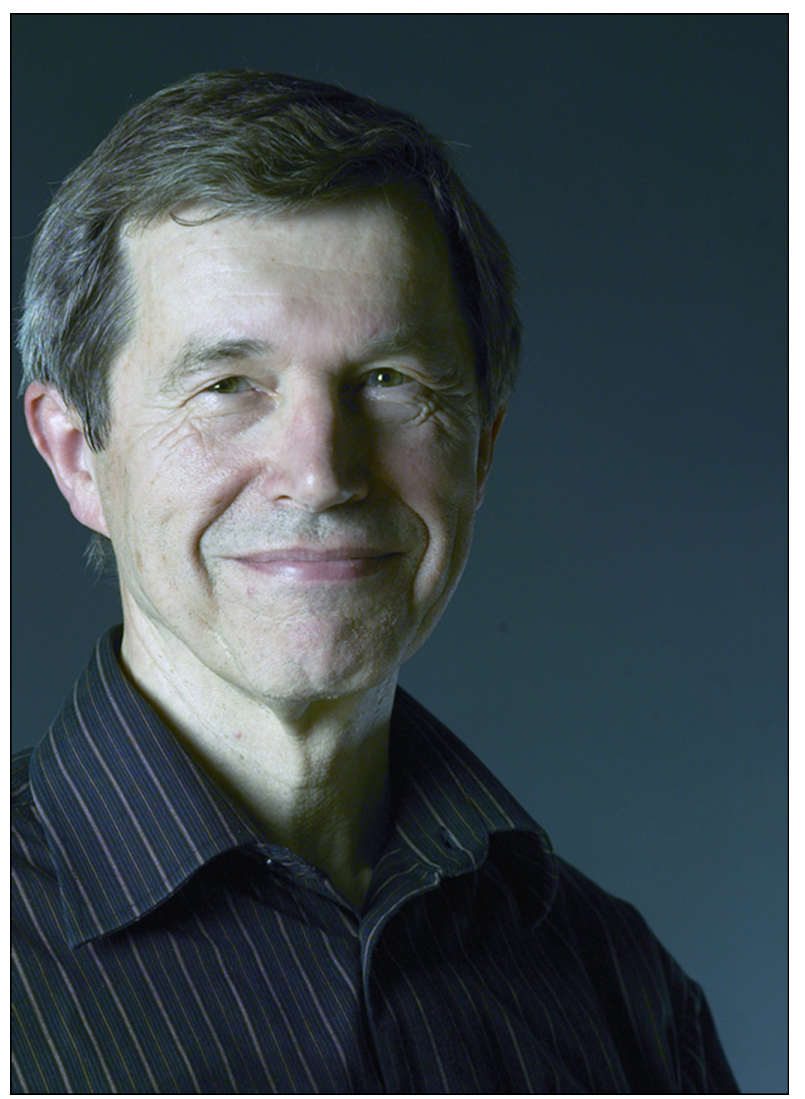

Fig. 1. Niels E. Skakkebaek was born in 1936 in Vodskov (Ålborg), Denmark. He graduated from the Medical School, University of Copenhagen in 1965, and received his Doctor of Medical Sciences degree on Studies on meiotic chromosomes in infertile males in 1974. He served as the Professor of Pediatrics, University of Copenhagen, in Fuglebakken Children's Hospital and Hvidovre Hospital 1982 - 1990. He founded the Department of Growth and Reproduction in University of Copenhagen, Rigshospitalet, where he worked as the Professor and Chairman 1990-2006. He continues his work there as a research professor.
1980

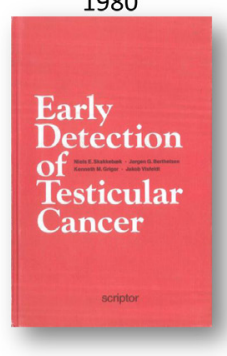

2002

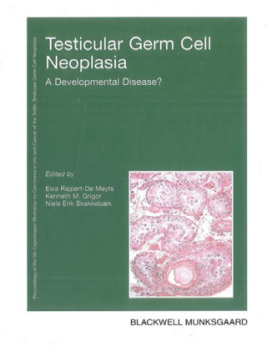

1986

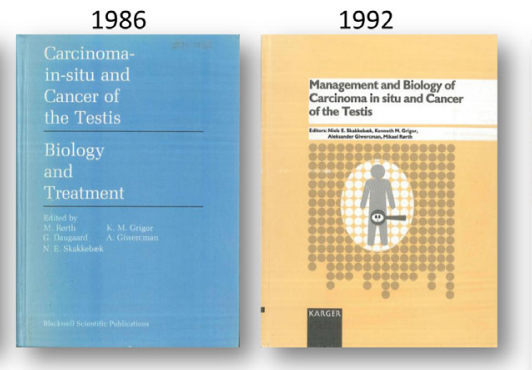

2006

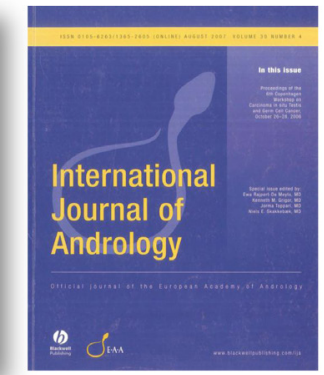

1997

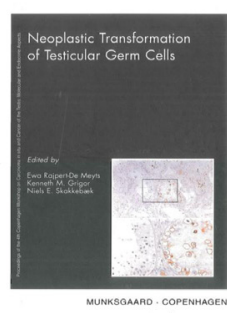

2010 colleague in Oncology Department, Mikael Rørth, the CIS theory had been accepted by most people working in the field. By that time enough evidence had been collected to launch the idea that CIS originated from fetal germ cells (Skakkebaek et al., 1987), a hypothesis that has then been tested in numerous papers from all over the world. Particularly the papers by Ewa Rajpert- De Meyts have provided basic molecular evidence for the fetal hypothesis (Rajpert-De Meyts, 2006).

This remarkable story, beginning in 1972, also became the basis of several important original clinical applications, including the early detection of testicular cancer by testicular biopsy in at risk groups (Berthelsen et al., 1982), and prevention of orchiectomy of the contralateral testis for the second neoplasia in that testis by localized irradiation if $\mathrm{CIS}$ was present (von deer Maase et al., 1986). The CIS work also changed chapters in textbooks on pathogenesis of testicular cancer (Skakkebaek and Berthelsen, 1981). Earlier it had been assumed that seminomas developed from intratubular germ cells, whereas other germ cell tumours had a different origin in blastomeres displaced in early embryonic life.

Skakkebaek has had the advantage that he is both a clinical endocrinologist and a basic researcher working with testicular specimens. The London based pathologist Connie Parkinson and her urological colleague Harland write in a commentary in Histopathology in 2002 (Skakkebaek, 2002): "The fact that, as a clinical endocrinologist, he (Skakkebaek) had the patient's complete histories may make histopathologists envious but in no way diminishes the clinic-pathological importance of his description and evidence-based proof of CIS of the testis"

The early findings from the 1970s have been followed up by numerous projects in the Copenhagen laboratory about CIS testis and testicular cancer, basic as well as clinical (Fig. 3). Jørn Müller worked on testicular samples from children and men with disorders of sex development (DSD) and characterized the ploidity in these cells. Aneuploidy was a frequent feature of the cells, further emphasizing the neoplastic nature of CIS (Müller and Skakkebaek, 1981). He also showed that children with androgen insensitivity syndrome had an increased risk to harbour CIS in their gonads (Müller and Skakkebaek, 1984; Müller et al., 1985). The same was true for those with gonadal dysgenesis and the 45,XO/46,XY karyotype. Søren Krabbe and Aleksander Giwercman showed that men with a history of cryptorchidism also had an increased risk to have CIS (Krabbe et al., 1979; Giwercman et al., 1987). All this fitted well to the epidemiological findings according to which these groups had an increased risk to develop testicular cancer. These early papers together with the basic research programme developed by Ewa Rajpert-De Meyts (See her article pp) led up to the current hypothesis of testicular dysgenesis syndrome (TDS) (Skakkebaek et al., 2001), by which testicular germ cell cancer is associated with impaired

Fig. 2. During the past 33 years the Copenhagen group has organized 7 international workshops on carcinoma in situ and cancer of the testis. The first was held in 1980 and the latest in 2010. The proceedings were published in various journals, including International Journal of Andrology, European Urology and APMIS. Dr. Kenneth M Grigor participated in all of them as the editor. 


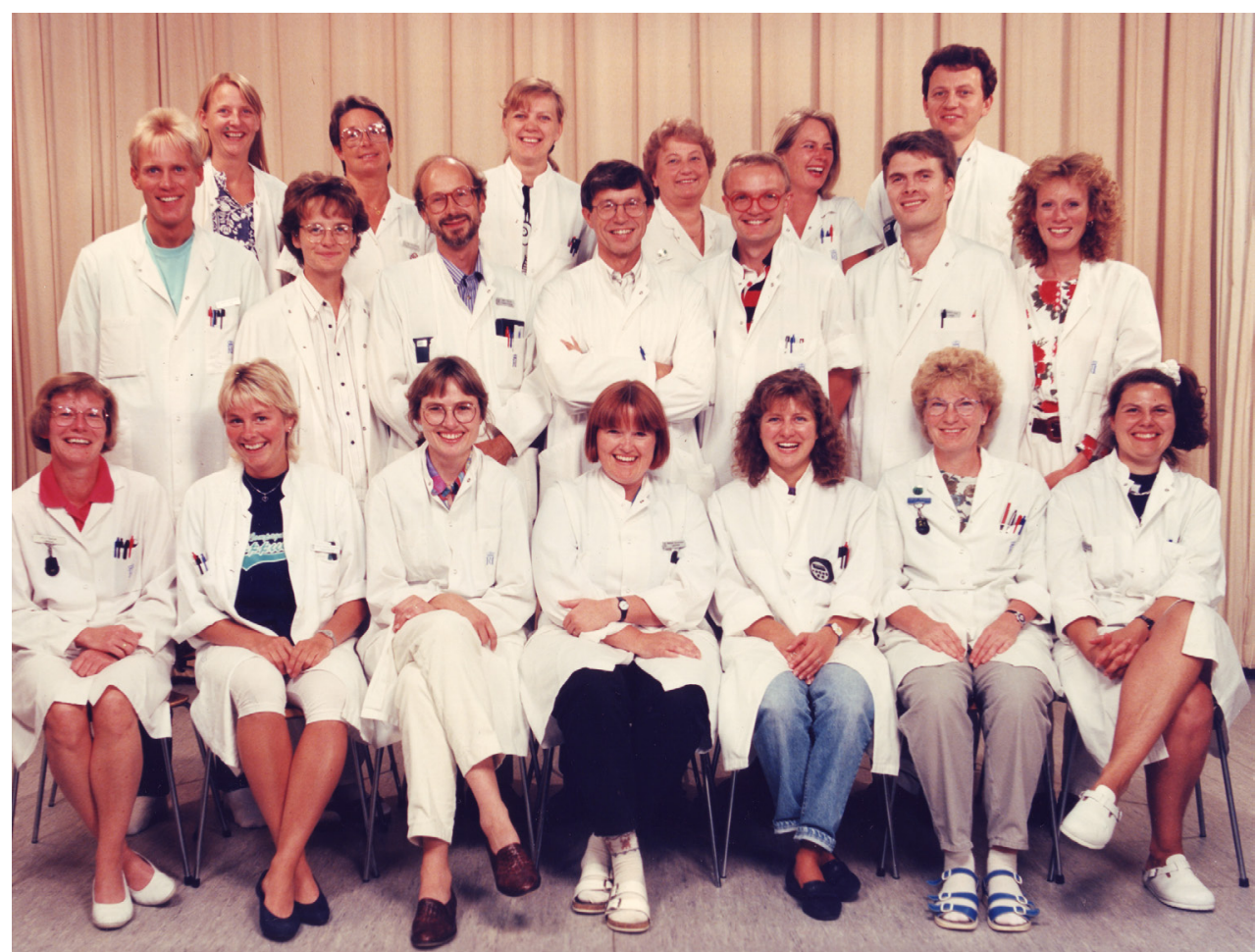

Fig. 3. Department of Growth and Reproduction at its early days in the 1990s when everybody looked still so young. Niels E. Skakkebaek stands in the centre with Jørn Müller on his right-hand side and Ewa Rajpert-De Meyts between them (behind). spermatogenesis, cryptorchidism and hypospadias, including some cases of DSD. According to the TDS hypothesis these disorders may have a common origin in the developing testis.

Thus a clinical science story on the origin of testicular germ cell cancer that started with a couple of infertile patients in 1972 has not yet come to the end. On the contrary, the Copenhagen CIS and testis cancer group is more active than ever, now with Ewa Rajpert-De Meyts as the chief for an extensive programme on germ cell cancer. The group is carrying out forefront translational research with a focus on the fetal hypothesis and possible roles of genetic and environmental factors in testicular germ cell cancer. In addition, a member of the group, Kristian Almstrup is leading a team attempting to diagnose CIS cells in semen of men with $\mathrm{CIS}$. Interestingly, the group has provided good evidence that CIS cells in some patients are exfoliated into seminal fluid. Rajpert-De Meyts and Almstrup found that this method is particularly relevant to use in screening of infertile men for germ cell neoplasia, the same population of patients from which Skakkebaek's first CIS patients were derived.

\section{Acknowledgements}

Toppari has received financial support from the Academy of Finland, the Sigrid Jusélius Foundation, the European Commission (FP7 DEER 212844), the Danish Council for Strategic Research and the Danish Agency for Science, Technology and Innovation (09-067180), and the Turku University Hospital.

\section{References}

BERTHELSEN JG, SKAKKEBÆKK NE, VON DER MAASE H, SØRENSEN BL, MOGENSEN P. (1982). Screening for carcinoma in situ of the contralateral testis in patients with germinal testicular cancer. Br Med J 285:1683-1686.

GIWERCMAN A, GRINDSTED J, HANSEN B, JENSEN OM, SKAKKEBEK NE. (1987). Testicular cancer risk in boys with maldescended testis: A cohort study. $J$ Urol 138:1214-1216.
KRABBE S, SKAKKEB/EK NE, BERTHELSEN JG et al., (1979). High incidence of undetected neoplasia in maldescended testes. Lancet $\mathrm{i}: 999-1000$.

MÜLLER J, SKAKKEBÆK NE, RITZÉN EM, PLÖEN L, PETERSEN KE. (1985). Carcinoma in situ of the testis in children with $45, X / 46, X Y$ gonadal dysgenesis. J Pediatr 106:431-436.

MÜLLERJ, SKAKKEBÆKKNE. (1981). Microspectrophotometric DNA measurements of carcinoma-in-situ germ cells in the testis. Int J Androl suppl.4:211-221.

MÜLLER J, SKAKKEBÆEK NE. (1984). Testicular carcinoma in situ in children with androgen insensitivity (testicular feminisation) syndrome. BrMed J288:1419-1420.

NIELSEN H, NIELSEN M, SKAKKEB/EK NE. T (1974). The fine structure of a possible carcinoma-in-situ in the seminiferous tubules in the testis of four infertile men. APMIS 82:235-248.

RAJPERT-DE MEYTS E. (2006). Developmental model for the pathogenesis of testicular carcinoma in situ: genetic and environmental aspects. Hum Reprod Update 12(3):303-323.

SKAKKEB/EK NE, BERTHELSEN JG, GIWERCMAN A, MÜLLER J. (1987). Carcinoma-in-situ of the testis: possible origin from gonocytes and precursor of all types of germ cell tumours except spermatocytoma. Int J Androl 10:19-28.

SKAKKEBÆEK NE, BERTHELSEN JG. (1981). Carcinoma-in-situ of the testis and invasive growth of different types of germ cell tumours. A revised germ cell theory. Int J Androl Suppl. 4:26-34.

SKAKKEBÆEK NE, RAJPERT-DE MEYTS E, MAIN KM. (2001). Testicular dysgenesis syndrome: an increasingly common developmental disorder with environmental aspects. Hum Reprod 16:972-978.

SKAKKEB/EK NE. (1972a). Abnormal morphology of germ cells in two infertile men. APMIS. 80:374-378.

SKAKKEB/EKNE. (1972b). Possible carcinoma-in-situ of the testis. Lancetii:516-517.

SKAKKEB/EK NE. (1975). Atypical germ cells in the adjacent "normal" tissue of testicular tumours. APMIS 83:127-130.

SKAKKEB/EK NE. (1978). Carcinoma in situ of the testis: frequency and relationship to invasive germ cell tumours in infertile men. Histopathology 2:157-170.

SKAKKEB/EK NE. (2002). Carcinoma in situ of the testis: frequency and relationship to invasive germ cell tumours in fertile men. N.E.Skakkebæk. Histopathology; 1978;2; 157-170 Author commentary. Histopathology 41:2-4.

VON DER MAASE H, GIWERCMAN A, SKAKKEBFK NE. (1986). Radiation treatment of carcinoma-in-situ of testis. Lancet i: 624-625. 
Further Related Reading, published previously in the Int. J. Dev. Biol.

Above the borderland between normal and neoplastic development

Juan Aréchaga and Ivan Damjanov

Int. J. Dev. Biol. (2012) 56: 939-948

Molecular and cellular machinery of gonadal differentiation in mammals

Rafal P. Piprek

Int. J. Dev. Biol. (2010) 54: 779-786

Analysis of SOX2 expression in developing human testis and germ cell neoplasia Si B. Sonne, Rebecca M. Perrett, John E. Nielsen, Melissa A. Baxter, David M. Kristensen, Henrik Leffers, Neil A. Hanley and Ewa Rajpert-De-Meyts

Int. J. Dev. Biol. (2010) 54: 755-760

Germinal tumor invasion and the role of the testicular stroma

Alejandro Díez-Torre, Unai Silván, Olivier De Wever, Erik Bruyneel, Marc Mareel and Juan Aréchaga

Int. J. Dev. Biol. (2004) 48: 545-557

The role of stem cell factor and of alternative c-kit gene products in the establishment, maintenance and function of germ cells

C Sette, S Dolci, R Geremia and P Rossi

Int. J. Dev. Biol. (2000) 44: 599-608

5 yr ISI Impact Factor $(2011)=2.959$
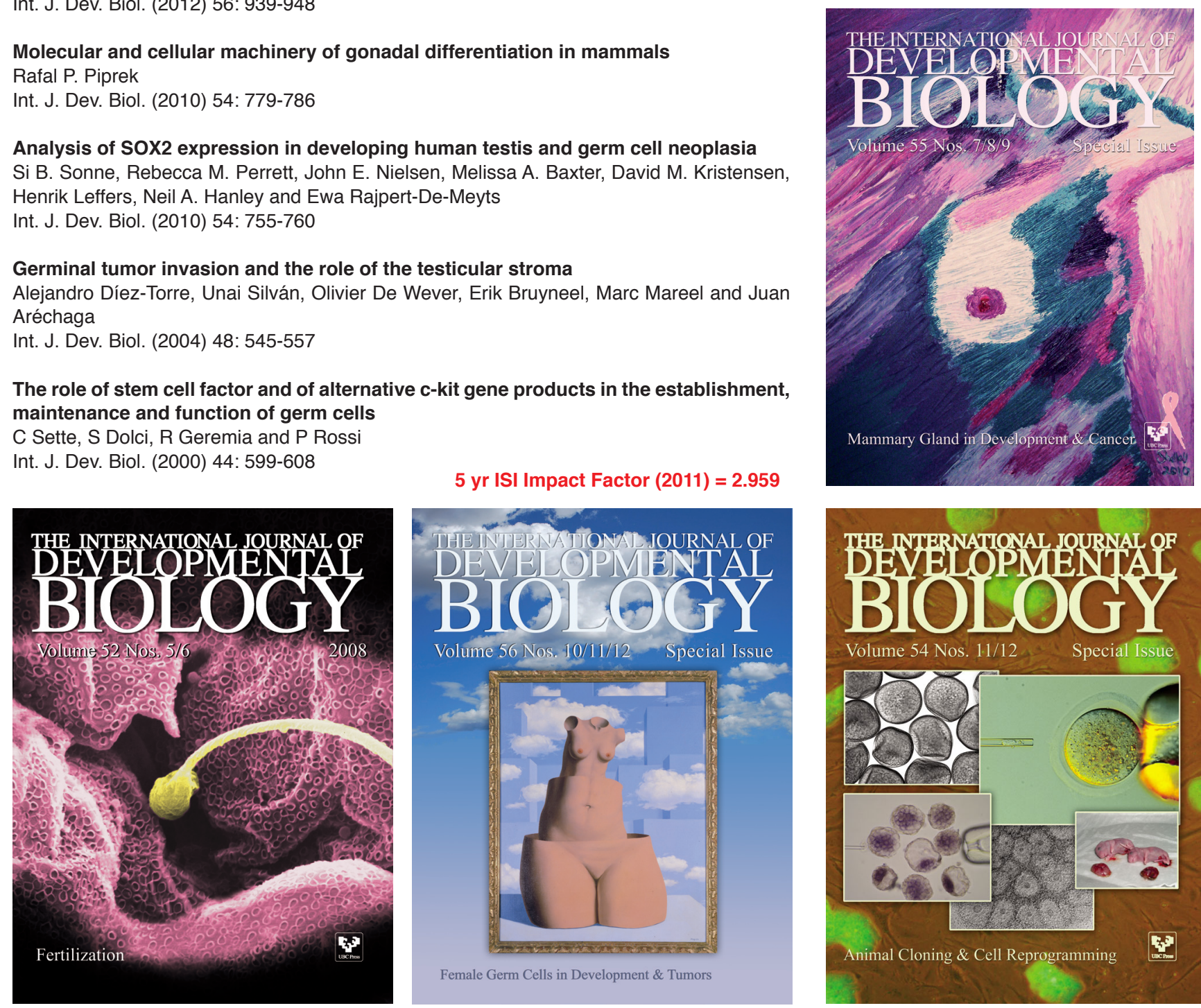

Volume 54 Nos. 11/12
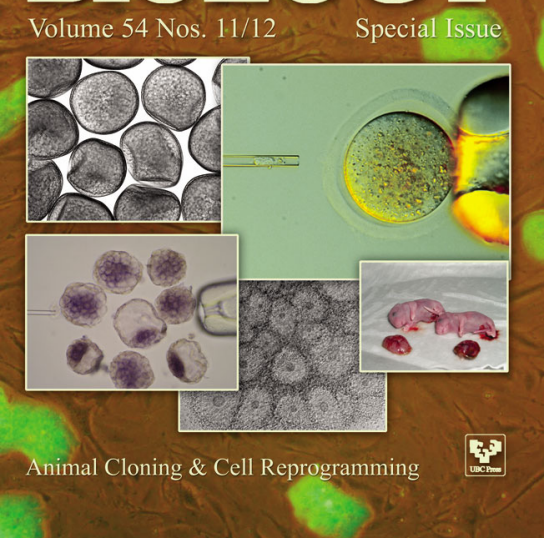